\title{
Vanadium Oxide Gel Films: Optical and Electrical Properties, Internal Electrochromism and Effect of Doping
}

\author{
E. L. Kazakova, O. Y. Berezina, D. A. Kirienko and N. P. Markova
}

\begin{abstract}
The sol-gel science and technology demonstrate an intense development over past few decades accompanied by important applications in electronics. The sol-gel technology represents a typical example of nanotechnology, since the gel products are actually nanocomposites or may contain nanoparticles. That is why the sol-gel science plays a crucial role in the $R \& D$ of contemporary nanotechnology for the fabrication of novel materials with new functional properties. In this paper we present an overview of our previous results on the properties of vanadium oxide gel structures, as well as report some recent findings in this area. Electrical and optical (including electrochromic effect) properties, influence of doping with tungsten and hydrogen, electrical switching. Moreover, the properties of vanadium oxide micro- and nanofibers are systematically described and discussed. Applied potentialities of the described phenomena for micro- and optoelectronics (electrochromic devices, sensors, electronic switches, etc) are also discussed.
\end{abstract}

Index Terms - Transition metal oxides, sol-gel, vanadium oxide, metal-insulator transition, electrochromic effect.

\section{INTRODUCTION}

$\mathrm{O}$ XIDES of transition metals (OTM), containing atoms with unfilled d-shells, possess multiple oxidation states and exhibit the phenomenon of mixed valence. Because of this property they are generally subject to various chemical and structural transformations under the action of different external perturbations, such as heat treatment, photon irradiation, electron and ion bombardment, or electrochemical treatment. These transformations, in turn, are accompanied by significant modifications of the optical, electrical and other properties [1]. The phenomenon of

Manuscript received May 20, 2014; accepted June 10, 2014. Date of online publication: June 30, 2014.

This work was supported by the Strategic Development Program of Petrozavodsk State University $(2012$ - 2016) and the RF Ministry of Education and Science as a part of state program in the scientific field, projects no. № 2014/154, № 3.757.2014/K.

E. L. Kazakova (ekazakova@psu.karelia.ru), O. Y. Berezina (berezina@psu.karelia.ru) and N. P. Markova (khomlyk@mail.ru) are with the Chair of General Physics, D.A. Kirienko (kirienko@ petrsu.ru) Chair of Information Measuring Systems and Physical Electronics. Department of Physical Engineering at Petrozavodsk State University, 185910 Petrozavodsk, Russia. electrochromism (EC) may serve as an example of such modification.

Of all the OTM, the vanadium-oxygen system is truly remarkable and even, in a certain sense, unique. The point is that vanadium forms more than ten distinct oxide phases with different electronic properties, ranging from metallic to insulating: $\mathrm{VO}, \mathrm{V}_{2} \mathrm{O}_{3}, \mathrm{VO}_{2}$, Magneli $\left(\mathrm{V}_{\mathrm{n}} \mathrm{O}_{2 \mathrm{n}-1}\right)$ and Wadsley $\left(\mathrm{V}_{2 \mathrm{n}} \mathrm{O}_{5 \mathrm{n}-2}\right)$ homologous series, and $\mathrm{V}_{2} \mathrm{O}_{5}$. Furthermore, a number of vanadium oxides undergo metal-insulator transitions at different temperatures. For instance, vanadium dioxide at $T<340 \mathrm{~K}$ is a semiconductor; at $T=T_{\mathrm{t}}=340 \mathrm{~K}$ the conductivity abruptly increases by four to five orders of magnitude, and above this transition temperature $\mathrm{VO}_{2}$ exhibits metallic properties [2].

The highest vanadium oxide, $\mathrm{V}_{2} \mathrm{O}_{5}$, has been shown to form, under certain conditions, new hybrid materials such as $\mathrm{V}_{2} \mathrm{O}_{5} \times n \mathrm{H}_{2} \mathrm{O}$ gels, which are actually composite materials made of solvent (water) molecules trapped inside an oxide $\left(\mathrm{V}_{2} \mathrm{O}_{5}\right)$ network [3]. Sol-gel chemistry is based on inorganic polymerization of organic precursors, in particular, metal alkoxides. Vanadium pentoxide gels can also be made directly from the oxide by means of, e.g. pouring the molten oxide into water (it is the so-called 'Muller's method' [3] or the quenching method [4]). Large quantities of these gels are prepared at present for industrial purposes [3]. Also, polymer-like $\mathrm{V}_{2} \mathrm{O}_{5} \times n \mathrm{H}_{2} \mathrm{O}$ can be prepared by hydration of amorphous $\mathrm{V}_{2} \mathrm{O}_{5}$ under controlled water vapor pressure [5].

Among different alternative routes for the vanadium oxide sol preparation, the acetylacetonate chemical method possess some merits, such as direct formation of the vanadium dioxide phase (without intermediate formation of $\mathrm{V}_{2} \mathrm{O}_{5}$ and subsequent reduction) and convenience of doping by various elements in a wide impurity concentration range [6], [7]. Although in the acetylacetonate sol-gel method, as was said, the stage of reduction annealing for the $\mathrm{V}_{2} \mathrm{O}_{5}-$ to$\mathrm{VO}_{2}$ transformation is not required, a certain thermal treatment process is still necessary for organic residua removal and oxide crystallization.

The physical properties of the $\mathrm{V}_{2} \mathrm{O}_{5}$ gels can be briefly summarized as follows [1], [3], [8], [9]. When dried under ambient conditions, the xerogels contain about $\mathrm{n}=1.6-1.8$ $\mathrm{H}_{2} \mathrm{O}$ per $\mathrm{V}_{2} \mathrm{O}_{5}$. Water can be removed upon heating to $\mathrm{n}=$ 
$0.5\left(T=120^{\circ} \mathrm{C}\right)$ and to $\mathrm{n}=0.1-0$ at $T=210-270^{\circ} \mathrm{C}$. Amorphous $\mathrm{V}_{2} \mathrm{O}_{5}$ is obtained at this temperature, and crystallization into orthorhombic $\mathrm{V}_{2} \mathrm{O}_{5}$ occurs around $350^{\circ} \mathrm{C}$. Vanadium dioxide can be easily prepared by a thermal treatment at $T \sim 500^{\circ} \mathrm{C}$ in vacuum or a reducing atmosphere [4], [10], [11]. The formation of $\mathrm{VO}_{2}$ rather than other lower vanadium oxides is accounted for by its thermodynamic properties [12], and preparation of other vanadium oxides in a thin film form is very difficult due to the narrowness of the stability range of any oxide [1], [12]. From the viewpoint of the atomic structure, the $\mathrm{V}_{2} \mathrm{O}_{5}$ gel belongs to a class of amorphous materials, but, unlike conventional inorganic glasses, it is closer to polymers or liquid crystals [3]. $\mathrm{V}_{2} \mathrm{O}_{5}$ layers are formed by cross-linked filaments and separated by water molecules (Fig. 1). The interlayer spacing is $11.3-11.5 \AA$ for the equilibrium singlephase xerogel with $n=1.6-1.8$. It depends on the water content and decreases by steps of $2.8 \AA$ as water is removed. For example, in [10] the spacing has been measured to be $11.55 \AA$ and $8.75 \AA$ for $\mathrm{n}=1.6$ and 0.5 , respectively.

$\mathrm{V}_{2} \mathrm{O}_{5}$ gels exhibit electronic properties arising from electron hopping through the mixed-valence oxide network as well as ionic conductivity properties arising from proton diffusion in the aqueous phase [1], [3], [13]-[15]. Roomtemperature conductivity ranges from $10^{-6}$ to almost $1 \Omega^{-1} \mathrm{~cm}^{-1}$. Experimental values depend on many parameters such as the state of reduction of vanadium $C$ (i.e. the relative amount of $\mathrm{V}^{4+}$ ), the hydration state (n), the atmospheric humidity, the age of the film, etc. Anisotropy of up to four orders of magnitude (parallel and perpendicular to the filaments) is observed. Ionic conduction prevails for $\mathrm{n}>0.5$ and can reach $10^{-2}$ $\Omega^{-1} \mathrm{~cm}^{-1}$. The activation energy, $\mathrm{W}$, is about $0.4 \mathrm{eV}$ at room temperature. Electronic conduction prevails in partially dehydrated xerogels $(\mathrm{n} \leq 0.5)$ with a high enough degree of reduction $(C>1 \%)$. The hopping conductivity is described by the small polaron model with the activation energy $W \sim$ $0.2 \mathrm{eV}[13]$.

Vanadium oxide gel films also exhibit electrochromic (EC) properties. Cyclic voltammetry experiments [3] have shown that $\mathrm{Li}+$ ions can be reversibly inserted within these films from an electrolyte (e.g. from a $1 \mathrm{M}$ solution of $\mathrm{LiClO}_{4}$ in propylene carbonate). Upon reduction, the films turn from yellow to green and blue. The EC properties of OTM $\left(\mathrm{WO}_{3}, \mathrm{Nb}_{2} \mathrm{O}_{5}, \mathrm{TiO}_{2}, \mathrm{MoO}_{3}\right.$ and some others) have been extensively studied in recent years [14]. The best investigated and the most common oxide among them is $\mathrm{WO}_{3}$. Vanadium oxide has also been shown to exhibit largely promising EC properties [16]-[20] and to have high potential for use in display devices, 'smart' windows and variable reflectivity mirrors, controllable color filters, etc [11], [21]. EC coloring/bleaching due to the $\mathrm{H}^{+}$and $\mathrm{Li}^{+}$ insertion/extraction has been studied in amorphous (anodic) vanadium oxide, polycrystalline films prepared by various techniques [16]-[19] and in sol-gel derived vanadium pentoxide layers [3], [11], [20].

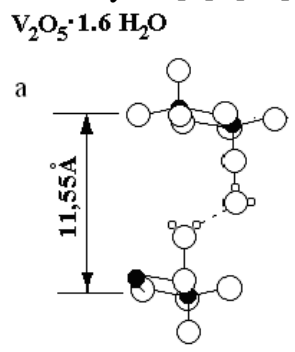

$\mathrm{V}_{2} \mathrm{O}_{5} \cdot 0.5 \mathrm{H}_{2} \mathrm{O}$
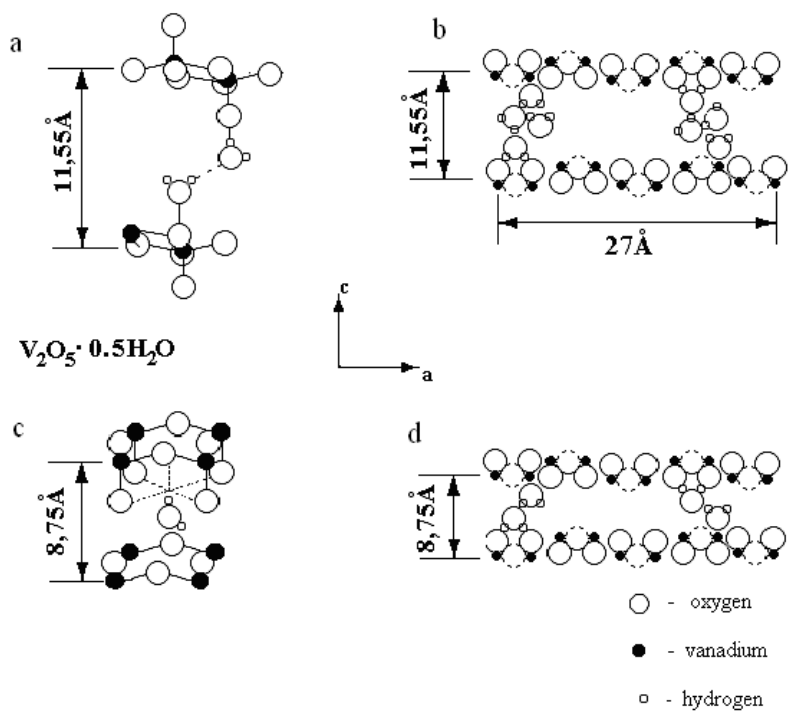

e

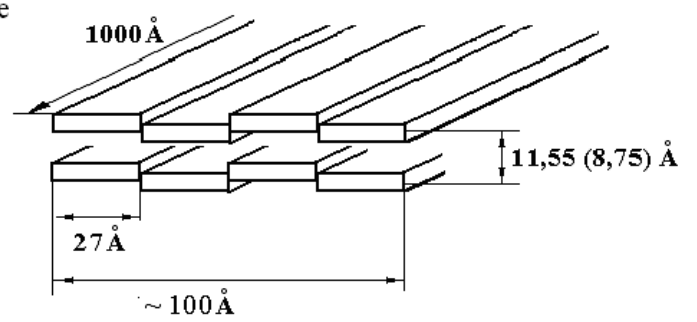

Fig. 1. Structure of $\mathrm{V}_{2} \mathrm{O}_{5} \times n \mathrm{H}_{2} \mathrm{O}$ xerogel with different water content (a, b) and (c, d), and a schematic picture of the structure layers (e) [15].

Another electrochemical process occurring in vanadium oxide gel films is the process of electroforming (EF) [1], [3], [22], [23]. Two-terminal planar switching devices based on $\mathrm{V}_{2} \mathrm{O}_{5} \times n \mathrm{H}_{2} \mathrm{O}$ have been reported in [23]. Reversible switching between ON and OFF states is observed after the device is preliminarily over-biased to a value about twice the switching voltage. As a result of such $\mathrm{EF}$, a narrow channel is formed in the gap between the electrodes. This channel has been shown to consist of vanadium dioxide, and the switching phenomenon is then associated with an electro-thermally driven metal-insulator transition in the channel.

Vanadium pentoxide gel films and fibers find a use in multiple areas such as, e.g., gas sensors, reversible cathode materials for Li batteries, and electrochromic devices [1], [9]. $\mathrm{V}_{2} \mathrm{O}_{5}$ has also been shown to be suitable for biological macromolecules encapsulation [24]. It is quite obvious that, in order to combine vanadium oxides with nanoscale integrated optoelectronic devices, it is necessary to produce these materials in the form of thin films and nanostructures. Considerable efforts have been made in this direction over the last decades, however, in comparison, for example, with bulk $\mathrm{VO}_{2}$ single crystals, where the MIT is accompanied by a sharp conductivity change within a very narrow 
temperature range at $T=T_{\mathrm{t}}$, thin films and nano-fibers typically show more spread out transitions and less significant changes in physical properties which is associated with the different factors affecting the transition, such as non-stoichiometry, defects, crystallite grain boundaries, structural disorder, and dimensional effects [25]. That is why the search for optimal conditions to fabricate more and more perfect vanadium oxide thin films and micro-fibers, on the basis of the sol-gel process, continues to be an important problem.

\section{SAMPLE PREPARATION AND EXPERIMENTAL METHODS}

Vanadium oxide samples were prepared by the sol-gel method. As was said in Section 1 above, this method is currently considered as a novel and efficient technique to prepare thin films of diverse materials, most of all oxides. In this process, thin films of metal oxides can be deposited directly on the immersed substrate or by spin-coating [1], [9]-[11]. Among other advantages of this method one can point out that it is easy to apply to various kinds of substrates with a large surface area and complex surface shape. Also, an essential merit of the sol-gel method is the ease of doping - merely by adding corresponding quantities of a certain composition to the prepared sol.

For the study of optical and electrical properties of vanadium pentoxide xerogel films, vanadium pentoxide gel solution was prepared by the quenching method. In this method, $\mathrm{V}_{2} \mathrm{O}_{5}$ powder was placed in a ceramic crucible and heated in air at $900^{\circ} \mathrm{C}$ (above the melting point, $690^{\circ} \mathrm{C}$ ) for an hour and then quenched by pouring the molten oxide into room temperature distilled water. After cooling down, a few milliliters of this gel solution were placed onto a substrate and excess solvent was allowed to evaporate at room temperature for $24 \mathrm{~h}$. As a result, yellowish-brown xerogel films were prepared with thicknesses, $d$, from $\sim 1 \mu \mathrm{m}$ to few tens of microns. The spin-coating deposition technique was also used to obtain thinner films ( $\mathrm{d} \leq 1 \mu \mathrm{m})$. These dried in air films represented $\mathrm{x}$-ray amorphous $\mathrm{V}_{2} \mathrm{O}_{5} \times n \mathrm{H}_{2} \mathrm{O}$ with $\mathrm{n}=$ 1.6-1.8; the interlayer spacing was measured to be $\sim 11.3 \AA$ from the (001) diffraction peak, using $\mathrm{MoK}_{\alpha}$ radiation. The $\mathrm{X}$-ray diffraction (XRD) pattern of the initial $\mathrm{V}_{2} \mathrm{O}_{5}$-gel film is presented in figure 2. Some samples were subjected to thermal treatment in a furnace at $100-300^{\circ} \mathrm{C}$ (in air) to obtain $\mathrm{n}<1.6$. The heating rate was very low, $\sim 0.5^{\circ} \mathrm{C} / \mathrm{min}$ in order to prevent blistering [4].

The substrates used were: (a) glass slides for optical transmittance measurements in the visible light region and for electrical measurements in planar structures; (b) those coated with thin film gold sub-layers for electrical measurements in sandwich structures; and (c) silicon (1.5 $\mathrm{cm} \times 2.5 \mathrm{~cm}$ pieces of $0.5 \mathrm{~mm}$ thick single-crystal wafers) for infrared (IR) transmittance measurements. In addition, vanadium oxide gel films were deposited onto flexible Kapton substrates.

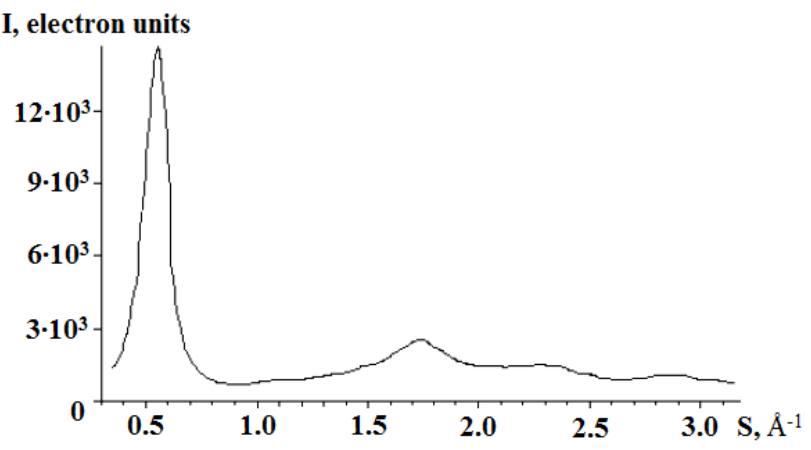

Fig. 2. X-ray intensity as a function of diffraction vector $\mathrm{s}=4 \pi \sin (\theta / \lambda)$ (where $\theta$ is the diffraction angle and $\lambda=0.7107 \AA-\mathrm{Mo}-\mathrm{K} \alpha$ radiation) for $\mathrm{V}_{2} \mathrm{O}_{5} \times n \mathrm{H}_{2} \mathrm{O}$ film.

Preliminary experiments have shown a strong influence of the choice of the metal sub-layer on the success of obtaining stable and reproducible switching, and gold has been found to be the most proper metal [26] among all the tested materials ( $\mathrm{Au}, \mathrm{Al}, \mathrm{V}, \mathrm{Cu}, \mathrm{Ni})$. The Au films on glass substrates, as well as aluminum electrical contacts on surfaces of vanadium oxide xerogel films, were obtained by thermal vacuum evaporation.

The IR transmittance of the films was recorded in the $400-4000 \mathrm{~cm}^{-1}$ range using a standard double beam spectrophotometer with a resolution of $4 \mathrm{~cm}^{-1}$. The measurements were performed with a pure Si substrate in the reference cell. The optical transmittance measurements in the visible were carried out in the wavelength range from 400 to $1100 \mathrm{~nm}$.

Electrical properties were examined by means of the a.c. and d.c. conductivity measurements, both in planar and in sandwich configurations. Aluminum contacts $1 \mathrm{~mm}$ in diameter (as well as, in some cases, spring-loaded gold wire 'point' contacts) were used to connect the samples with the external circuit. The a.c. conductivity was measured using an impedance meter in the frequency range $f=5-500 \mathrm{kHz}$ [1]. The diapasons of $Z$ and $\varphi$ were $1-10^{7} \Omega$ and $-90^{\circ}$ to $+90^{\circ}$, respectively (where $Z^{*}=Z \exp (i \varphi)=Z+i Z^{\prime}$ is the complex impedance), and the amplitude of the probing voltage was $3 \mathrm{mV}$ to $0.3 \mathrm{~V}$ (at $Z>0.1 \mathrm{M} \Omega$ ). The d.c. conductivity measurements were carried out using standard four- and two-probe techniques. The processes of modification of the $\mathrm{V}_{2} \mathrm{O}_{5}$ gel films under high electrical fields were studied using the current-voltage $(I-V)$ characteristic method and the optical and electrical measurements described above. EF and switching were also studied using $I-V$ measurements as described previously [26], [27].

In order to investigate the influence of doping on the properties of vanadium oxide gel films, vanadium pentoxide gel solution was prepared by the modified quenching method [10], [28]. Tungsten-doped gels were obtained by adding $\mathrm{WO}_{3}$ powder directly to the vanadium pentoxide melt. It had been found experimentally that the dissolution limit of $\mathrm{WO}_{3}$ in $\mathrm{V}_{2} \mathrm{O}_{5}$ melt corresponded to 12 at. \% of 
tungsten. In order to deposit a film, a few milliliters of the gel solution were placed onto a substrate and excess solvent was allowed to evaporate at room temperature for $24 \mathrm{~h}$. As a result, yellowish-brown xerogel films were prepared with a typical thickness $\mathrm{d} \sim 1-5 \mu \mathrm{m}$. These dried-in-air films represented x-ray amorphous $\mathrm{V}_{2} \mathrm{O}_{5} \times n \mathrm{H}_{2} \mathrm{O}$ with a layered structure [11].

The possibility of doping with hydrogen has been studied with samples of amorphous $\mathrm{V}_{2} \mathrm{O}_{5}$, obtained by the thermal treatment of an initial $\mathrm{V}_{2} \mathrm{O}_{5} \times n \mathrm{H}_{2} \mathrm{O}$ film in air at $T=250^{\circ} \mathrm{C}$. Plasma treatment has been performed in an RF $(2.45 \mathrm{GHz})$ hydrogen reactor with remote plasma [29], [30]. Design features of the reactor exclude the sample heating, permitting, however, its contact with low-energy $\mathrm{H}^{+}$ions and atomic hydrogen.

Vanadium oxide films and fibers were also prepared by an acetylacetonate sol-gel method, and the synthesis strategy included the following steps [7].

- Synthesis of vanadyl acetylacetonate (oxy-bis(2,4pentandione)-vanadium, $\left.\quad \mathrm{C}_{10} \mathrm{H}_{14} \mathrm{O}_{5} \mathrm{~V}, \quad \mathrm{VO}(\mathrm{acac})_{2}\right) \quad$ via interaction of $\mathrm{VOSO}_{4}$ with acetylacetone $\left(\mathrm{C}_{5} \mathrm{H}_{8} \mathrm{O}_{2}\right)$ followed by purification of the product.

- Preparation of the $\mathrm{VO}(\mathrm{acac})_{2}$ solution in methanol with a concentration of $0.125 \mathrm{~mol} /$ liter.

- Deposition of the VO(acac) $)_{2}$-methanol sol films onto silicon substrates by spin coating for 10-12 sec at $3000 \mathrm{rpm}$.

- IR drying at $150^{\circ} \mathrm{C}$ to remove the dissolvent and $\mathrm{VO}(\mathrm{acac})_{2}$ film formation.

The process of deposition (i.e. the two last steps) was repeated multiple to obtain a desired total film thickness (50 to $200 \mathrm{~nm}$ normally). Finally, the films were annealed in wet nitrogen under different temperature regimes in order to optimize the film structure and composition.

Vanadium oxide fibers were formed from a solution of $\mathrm{VO}(\mathrm{acac})_{2}$ in methanol, with addition of polyvinylpyrrolidone (PVP) polymer, by an electrospinning method [31]. The solution feed rate from the syringe was varied in the range of 0.05 to $0.50 \mathrm{ml} / \mathrm{hr}$. When preparing the samples for electrical measurements, a glass-ceramics substrate covered by pre-deposited gold contacts and an additional mask, was placed over the Al collector. The obtained fibers were then subject to further drying and heat treatment.

The samples obtained by the acetylacetonate method were characterized by XRD using a DRON-4 diffractometer (fibers) and a Rigaku D/MAX diffractometer (films), both with $\mathrm{Cu}-\mathrm{K}_{\alpha}$ radiation. The temperature dependences of resistance (by means of a four-probe technique) were measured using a Keithley 2410 SourceMeter supplied with a heater and copper-constantan thermocouple connected to a Keithley 2000 Multimeter. Current-voltage characteristics were measured with a Keithley 2636A SourceMeter. Fiber morphology was investigated by means of optical and scanning electron microscopy.

\section{RESULTS AND DISCUSSION}

\section{A. Electrical Properties}

In this subsection we describe the electrical properties of the films obtained by the melt method (Section 2) [1]. The as-prepared films have low conductivity. The d.c. roomtemperature resistance of the sandwich structures with a point contact is of the order of $10^{6}-10^{8} \Omega$. The temperature dependence $R(T)$ is quite similar to that reported in the literature [3], [13] and the activation energy is found to be $\sim 0.3 \mathrm{eV}$ [1]. Figure 3 shows the $I-V$ characteristic of a sandwich structure with the $\mathrm{V}_{2} \mathrm{O}_{5}$ gel film. One can see four distinct regions. The first (low voltage) corresponds to the Ohmic behavior. Then, at a certain voltage, some instabilities appear (region 2) and the $I-V$ curve becomes non-linear (region 3). The slope in bilogarithmic coordinates is $\sim 2$ (1.8-2.2 for different samples), i.e. $I \sim V^{2}$. This might suggest that in high fields the conductivity is determined by the space charge limited currents. And, finally, at a higher voltage, electrical breakdown or forming occurs (region 4) irreversibly, switching the device to a new, low-resistance state.

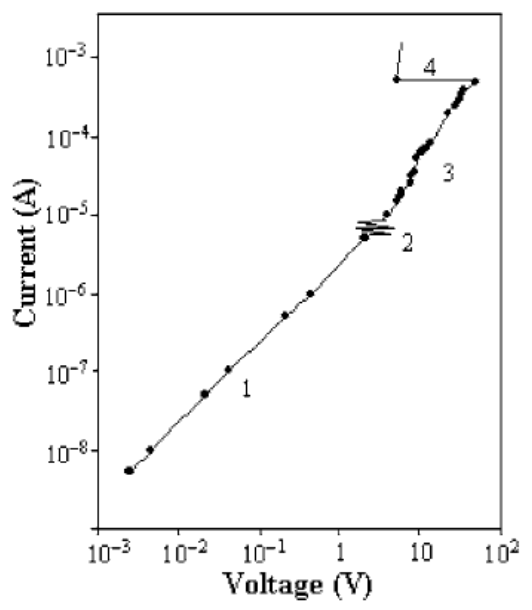

Fig. 3. $I-V$ characteristic of the $\mathrm{M} / \mathrm{xerogel} / \mathrm{M}$ sandwich structure with a point contact (taken from [1] with permission). $\mathrm{V}_{2} \mathrm{O}_{5}$ gel film thickness is $\mathrm{d}=8.4 \mu \mathrm{m} ; 1,2,3$, and 4 - see discussion in the text.

The same Ohmic behavior (with a certainly much higher resistance) is exhibited by the planar structures at measuring currents less than a certain critical value $I_{c}$. For example, $I_{c}$ is $\sim 1 \mu \mathrm{A}$ for $d \sim 1 \mu \mathrm{m}$ and a $1 \mathrm{~mm}$ gap between the contacts. However, at a high enough current density $I>I_{c}$ (corresponding to the region 2 in Fig. 3), visible changes in the optical properties of the films under the cathode are observed corresponding to the internal EC effect [1].

The a.c. measurements of the complex impedance as a function of frequency (on the sandwich structures) show that both $Z$ and $\tan [\delta](=\cot [\varphi])$ depend on $f$ (Fig. 4, a). The former smoothly decreases with increasing $f$, whereas the function of dielectric losses usually has a minimum at a certain $f \approx 1 \mathrm{kHz}(0.5-2 \mathrm{kHz}$ for different samples). The Cole-Cole diagram (Fig. 4, b) is similar to that for $\mathrm{V}_{2} \mathrm{O}_{5} \times 1.8 \mathrm{H}_{2} \mathrm{O}$ presented in [3], [32]. A straight line at low 
frequencies corresponds to the diffusion of charge carriers. However, the semicircle at higher frequencies cannot be associated with any dielectric relaxation process arising from the rotation of water molecules. Indeed, the first semicircle corresponding to the rotation of strongly bonded $\mathrm{H}_{2} \mathrm{O}$ molecules appears at much higher frequencies, $\sim 10^{7}-$ $10^{8} \mathrm{~Hz}$ [3]. This semicircle in figure 4(b) centered at $f \approx 10^{4}$ $\mathrm{Hz}$ is due to interfacial (Maxwell-Wagner) polarization [1]. This type of polarization is characteristic of heterogeneous, layered materials and related to space charge accumulation.

A similar approach to the analysis of the $\left(Z^{\prime}-Z^{\prime}\right)$ diagrams has been developed for sol-gel deposited proton conducting $\mathrm{V}_{2} \mathrm{O}_{5}$ [20] and $\mathrm{Ta}_{2} \mathrm{O}_{5}$ [33] films. In our case, however, it is impossible to use the standard electrochemical impedance spectroscopy [20], [33], because the system under study does not contain an electrolyte, and it represents a $\mathrm{M} / \mathrm{V}_{2} \mathrm{O}_{5} \times n \mathrm{H}_{2} \mathrm{O} / \mathrm{M}$ sandwich structure with ion-blocking electrodes. Therefore, to interpret the results on $Z^{*}(f)$, we used conventional considerations commonly accepted in the physics of dielectrics [34], i.e. the analysis based on an equivalent circuit. The model circuit is depicted in Fig. 5, inset of panel (b), where $R$ is the Ohmic resistance modeling the electronic conductivity, $r$ corresponds to the ionic (proton) conductivity, and $C$ is the overall geometric capacitance of the $\mathrm{M} / \mathrm{V}_{2} \mathrm{O}_{5} \times n \mathrm{H}_{2} \mathrm{O} / \mathrm{M}$ structure. That the resistor $r$ is connected in series with $C$, indicates also the absence of the d.c. ionic current: $\sigma_{\mathrm{i}}(f)=0$ at $f \rightarrow 0$. Such an equivalent circuit is usually used for description of the systems exhibiting the behavior with the minimum of $\tan \delta(f)$ - see Fig. 4, a. The function of dielectric losses for this circuit can be written as:

$$
\tan \delta=(1+\alpha) \omega \tau+\frac{\alpha}{\omega \tau},
$$

where $\alpha=r / R, \omega=2 \pi f$ and $\tau=r C$. The condition of minimum for Equation (1) yields the frequency $f_{m}$ and the value of $\tan \delta$ at $f=f_{m}$ :

$$
f_{\mathrm{m}}=(2 \pi \tau)^{-1}\left[\frac{\alpha}{\alpha+1}\right]^{1 / 2}, \quad(\tan \delta)_{\mathrm{m}}=2[\alpha(\alpha+1)]^{1 / 2}
$$

From Equations (2), along with the expression for $Z\left(f_{m}\right)$, one can obtain the values of $R, r$ and $C$ at $f=f_{m}$. In order to get the frequency dependences of all the three parameters, a dispersion law of at least one of them should be known, because in the whole frequency range we have only two equations, $Z(f)$ and $\varphi(f)$. We therefore assume that the electronic conductivity is proportional to $\omega^{s}$, i.e. $R \sim 1 / \omega^{s}$. This assumption appears to be reasonable, because as such the dependence corresponds to the hopping mechanism of conductivity. The exponent $s$, for a wide class of amorphous materials, is equal to about $0.7-0.9$ [35].

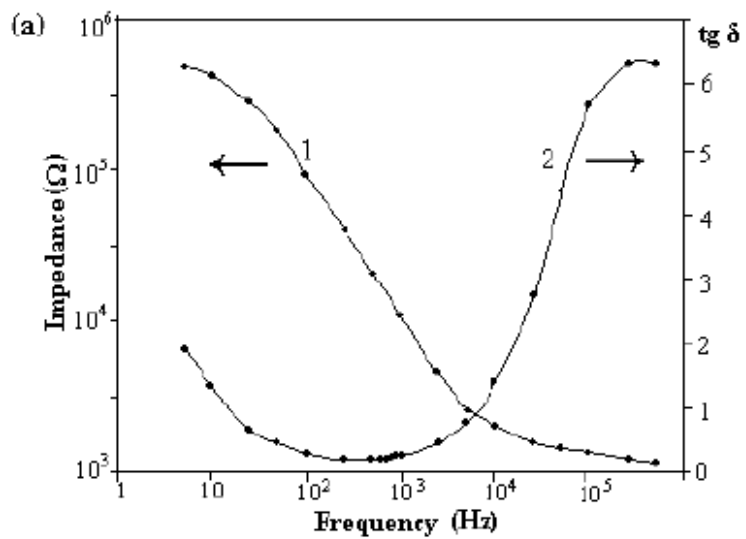

(b)

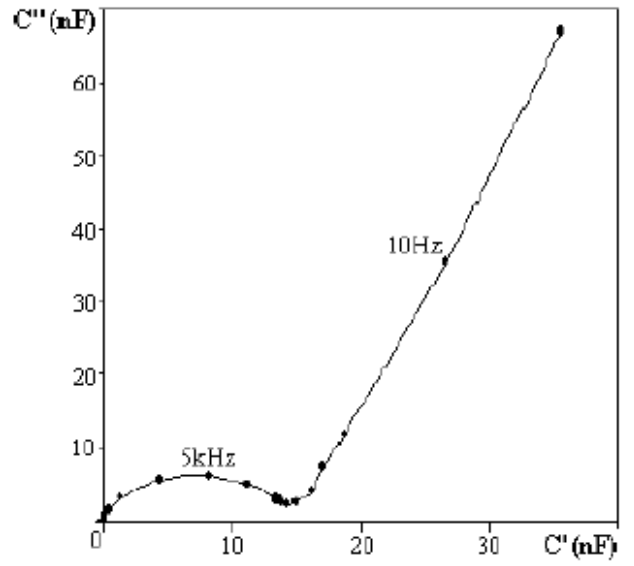

Fig. 4. A.c. impedance spectroscopy data for the $\mathrm{V}_{2} \mathrm{O}_{5}$ xerogel film, $d=$ $8.4 \mu \mathrm{m}$ : (a) $1-\left|Z^{*}\right|$ and 2 - dielectric losses as functions of frequency, and (b) Cole-Cole diagram, where $C^{\wedge}=-\sin (\varphi) / \omega Z$ and $C^{\prime \prime}=\cos (\varphi) / \omega Z$ (taken from [1] with permission).

In order to reinforce this hypothesis, we carried out an additional experiment. One of the samples was annealed at $310^{\circ} \mathrm{C}$ to remove water and exclude thereby the ionic conductivity. The high-frequency dependence of $\log (\sigma)$ on $\log (\omega)$ was actually linear in this case with the slope $s=$ $0.71 \pm 0.07$ (Fig. 5, a). Numerical simulations showed, however, that the results of calculations were almost independent of the exact value of $s$ when it was varied in the range from 0.5 to 1 and we then used for calculations $s=0.7$.

The results of calculations for ionic conductivity are presented in Fig. 4, b. One can see that the value of ionic conductivity increases upon coloration. The average value of $R$ corresponding to the electronic conduction does not change (within experimental error) and equals about $5.4 \times 10^{5} \Omega$ at $f=250 \mathrm{~Hz}$. The equivalent capacitance depends slightly on frequency, and in the range $10^{2}-10^{5} \mathrm{~Hz}$ it is almost constant, $\sim 1.5 \times 10^{-8} \mathrm{~F}$. At higher frequencies, the value of $C$ sharply falls down to $10^{-9}-10^{-10} \mathrm{~F}$ at $f=5 \times 10^{5}$ $\mathrm{Hz}$ for the initial sample, whereas for the colored sample it remains $\sim 10^{-8} \mathrm{~F}$. For the film thickness $d=8.4 \mu \mathrm{m}$, this $C$ yields the dielectric constant $\varepsilon \approx 10^{4}$. Such a high effective dielectric permittivity, $\sim 10^{3}-10^{4}$, is characteristic of heterogeneous systems with Maxwell-Wagner polarization mechanisms [1], [34]. 
(a)

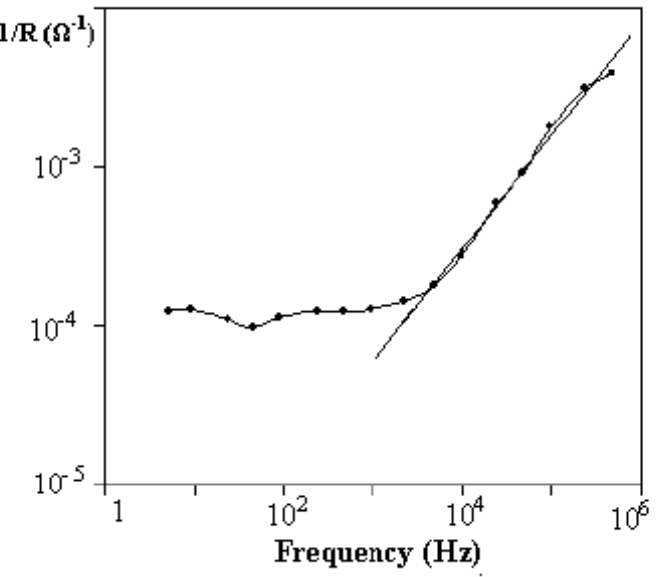

(b)

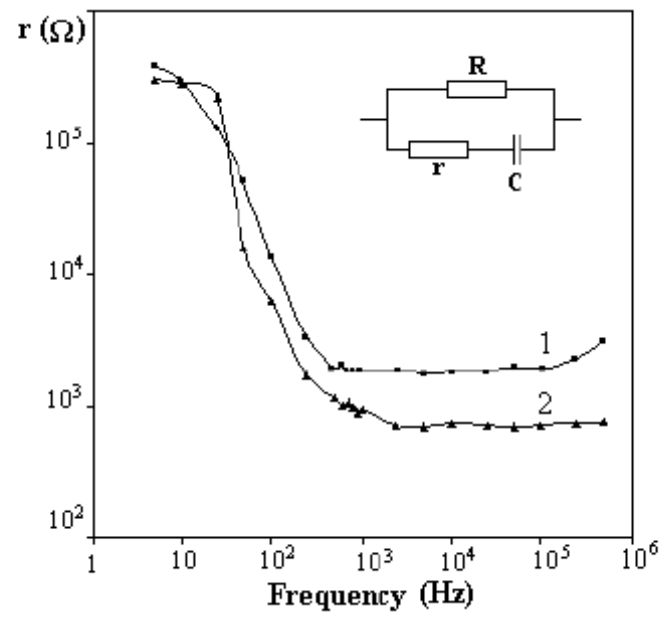

Fig. 5. (a) A.c. conductivity of the annealed (dehydrated) film and (b) series resistance $r$ as a function of frequency calculated from the data of figure 4(a); 1-initial film, 2-after coloration (taken from [1] with permission). The equivalent circuit is shown in the inset of part (b)

The discussion and analysis of the results presented in this subsection show [1] that cathodic polarization of the $\mathrm{V}_{2} \mathrm{O}_{5} \times n \mathrm{H}_{2} \mathrm{O}$ films results in the following changes in the electrical properties: (i) rise of the ionic conductivity ( $\sigma_{\mathrm{i}}$ of the colored film is almost threefold higher); (ii) some changes in the magnitude and frequency dependence of the dielectric permittivity; and (iii) the value of $R$, corresponding to the electronic conductivity, is found to remain practically unchanged. Thus, although the ionic conductivity of the samples under study is less than that of the standard $\mathrm{V}_{2} \mathrm{O}_{5}$ xerogel, it is relatively high and comparable with $\sigma_{\mathrm{i}}$ of such materials as solid electrolytes, superionic conductors, or growing anodic oxide films. This high ionic (proton) conduction is, in fact, responsible for the reported internal EC effect, which will be described in detail in the next subsection.

\section{B. Optical Properties and Electrochromic Effect}

As it was already said, for the planar structures, when measuring currents at a high enough current density $I>I_{c}$, we encountered visible changes in the optical properties of the films under the cathode. A red spot, gradually increasing
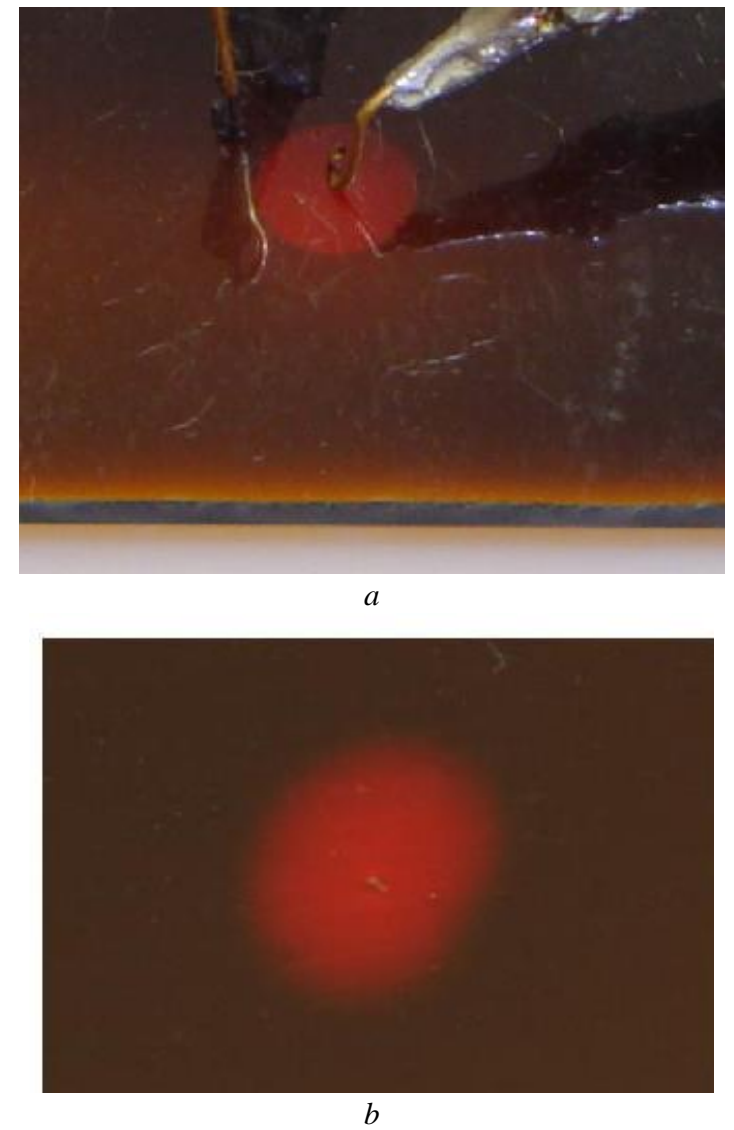

Fig. 6. (a) The process of coloration and (b) colored region $(\sim 5 \mathrm{~mm}$ in diameter)

in diameter, was observed as the current flowed (Fig. 6).

The time of the spot appearance, as well as its diameter, depend on the current value and on the overall duration of the electric-field treatment. This phenomenon is similar to EC effect, but it occurs without an external electrolyte and has therefore been termed as the 'internal EC effect' [1].

The transmittance spectra of the initial and colored regions for one of the samples are presented in Fig. 7. Standard conditions of coloration were as follows: $I=1.0$ $10 \mu \mathrm{A}$ and the process duration was typically about $10 \mathrm{~min}$. For the sample in Fig. 7, $d=4 \mu \mathrm{m}$, and the size of the colored region $D \approx 2 \mathrm{~mm}$.

At the reverse polarity, the spot disappears, i.e. the process of bleaching takes place. For the samples subjected to a preliminary heat treatment at $T>300^{\circ} \mathrm{C}$ (in order to remove water), EC coloration no longer occurs. This suggests that the intrinsic water plays an important role in the process of internal EC coloration of hydrated vanadium oxide. It is pertinent to note that for the fresh samples (i.e. for those studied right after the drying is finished), as well as for the thicker films, the effect was also weak or even altogether absent, likewise for the annealed films. However, this is related to poor optical contrast, since such films (fresh or sufficiently thick) are initially dark reddish-brown, not yellow-brown. 


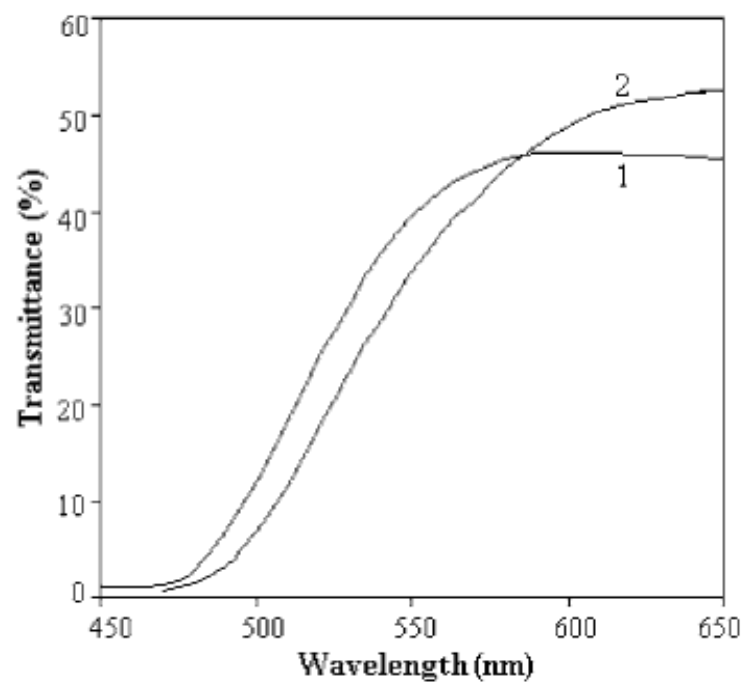

Fig. 7. Transmission spectra of the as-prepared (1) and colored (2) film, $d$ $=4.0 \mu \mathrm{m}$. Coloration regimes: $I=10 \mu \mathrm{A}, t=10 \mathrm{~min}$; planar configuration (taken from [1] with permission).

The optical transmittance spectrum of the as-prepared $\mathrm{V}_{2} \mathrm{O}_{5} \times n \mathrm{H}_{2} \mathrm{O}$ film on a glass substrate is presented in Fig. 7, curve 1 . As one can see from the figure, the spectra exhibit a characteristic absorption band at a wavelength of about $500 \mathrm{~nm}$. For the colored samples, an increase in $T$ (approximately from 40 to $50 \%$ ) and a shift of the absorption edge towards longer wavelengths are observed.

The absorption edge at $2.3-2.5 \mathrm{eV}$ in vanadium-oxygen compounds is ascribed to $\mathrm{O} 2 \mathrm{p} \rightarrow \mathrm{V} 3 \mathrm{~d}$ electron transitions and it is consistent with the energy gap of $\mathrm{V}_{2} \mathrm{O}_{5}, E_{g}=2.35$ $\mathrm{eV}$, and $\mathrm{V}_{2} \mathrm{O}_{5} \times n \mathrm{H}_{2} \mathrm{O}, E_{g}=2.49 \mathrm{eV}$ [1]. Modification of the optical properties near the fundamental absorption band is thus associated with a distortion of the main structural element ( $\mathrm{V}-\mathrm{O}$ polyhedra) due to the cation intercalation. However, unlike the usual EC effect, in this case, the hydrogen ions are not inserted from the outside, i.e. from an electrolyte, but they are redistributed inside the sample under the action of the electric field.

Indeed, it is known that vanadium pentoxide xerogel contains hydrogen (both in $\mathrm{H}_{2} \mathrm{O}$ groups, and as free hydrogen atoms or $\mathrm{H}^{+}$ions) and generally possesses high ionic conductivity at room temperature [3]. In fact, vanadium pentoxide gels can be described as polyvanadic acid $\mathrm{H}_{\mathrm{x}} \mathrm{V}_{2} \mathrm{O}_{5} \times n \mathrm{H}_{2} \mathrm{O}$ with $\mathrm{x}=0.3-0.4$ [3], [16] (formally, such a compound may also be considered as a hydrogen bronze of $\mathrm{V}_{2} \mathrm{O}_{5}$ gel). Obviously, during the $\mathrm{EC}$ coloration, an increase in hydrogen concentration in electric field occurs in the vicinity of the cathode, which is also supported by the results on $\sigma_{i}$, Fig. 5, b:

$$
\mathrm{H}_{\mathrm{x}} \mathrm{V}_{2} \mathrm{O}_{5} \times n \mathrm{H}_{2} \mathrm{O}+\mathrm{zH}^{+}+\mathrm{ze}^{-} \rightarrow \mathrm{H}_{\mathrm{x}+\mathrm{z}} \mathrm{V}_{2} \mathrm{O}_{5} \times n \mathrm{H}_{2} \mathrm{O} .
$$

The hydrogen abundance in the coloured film can be estimated from the value of the charge which has percolated throughout the circuit (assuming a $100 \%$ efficiency for reaction (3)):

$$
z=\frac{4 I t \mu}{q \rho \pi D^{2} d N_{A}},
$$

where $\mu=214 \mathrm{~g} \mathrm{~mol}^{-1}$ (for $\mathrm{n}=1.8$ ) and $\rho=3.09 \mathrm{~g} \mathrm{~cm}^{-3}$ are, respectively, the molecular weight and density of hydrated $\mathrm{V}_{2} \mathrm{O}_{5}$, $\mathrm{q}$ is the charge of an ion $\mathrm{H}^{+}$(and It/q is the total number of the extra hydrogen ions), $N_{\mathrm{A}}$ is the Avogadro number. $D$ is the diameter of the colored region, and $d\left(\pi D^{2} / 4\right)$ is its volume. For one of the samples (Fig. 7), calculations from Equation (4) yield $z=0.34$. That this is a reasonable result is supported by the fact that it is in agreement with the data on $\mathrm{Li}$ intercalation (maximum $z$ is 0.8-1.0) and on $\mathrm{H}$ intercalation, for which the hydrogen concentration may be as large as $z=4$ for anodic vanadium oxide [1].

However, unlike conventional EC coloration (with an external electrolyte) of $\mathrm{V}_{2} \mathrm{O}_{5}$ derived from gel, the color change in our case is not 'yellow $\rightarrow$ green' [3], [16], but it is quite the reverse, i.e. 'yellow $\rightarrow$ red'. Note that the same 'red shift' as in this paper has been observed also only in the work [20] - see Fig. 8, curves 3 and 4. We surmise that this difference is due to the presence of water in the samples. In [20] the samples of $\mathrm{V}_{2} \mathrm{O}_{5}$ were prepared from gel and annealed at relatively low temperatures, $300^{\circ} \mathrm{C}$, in order to obtain amorphous films. One can suppose that some trace amount of water $(n \leq 0.1)$ might persist in the films after this thermal treatment. Thus, we can conclude that the EC effect in $\mathrm{V}_{2} \mathrm{O}_{5} \times n \mathrm{H}_{2} \mathrm{O}$ (unlike pure $\mathrm{V}_{2} \mathrm{O}_{5}$ ) is conditioned not only by the $\mathrm{H}^{+}$(or $\mathrm{Li}^{+}$) concentration change, but also, presumably, by the change in the value of $n$ (water content).

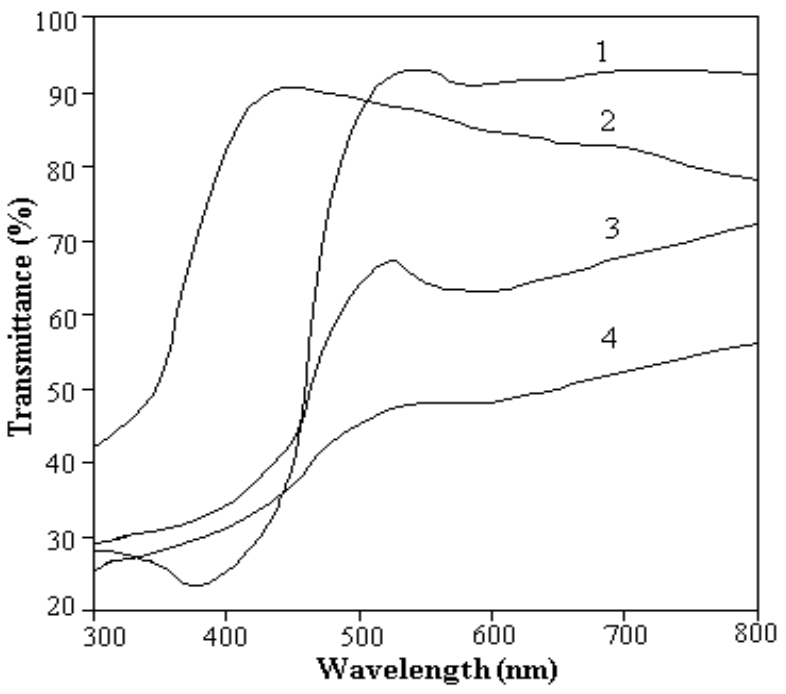

Fig. 8. Transmittance vs. wavelength for initial $(1,3)$ and colored $(2,4)$ vanadium pentoxide films by the electrochemical $\mathrm{Li}$ insertion, from [16] and [21] (curves 1 and 2) and [20] (3 and 4).

The XRD measurements revealed that the interlayer spacing increased from 11.3 to $11.5 \AA$ during coloration, that could actually indicate some increase of the water 
content [1], [7]. Farther, according to the IR spectroscopy data, during coloration the intensities of the 3300 and 1550 $\mathrm{cm}^{-1}$ bands in the IR spectra, corresponding, respectively, to the $\mathrm{O}-\mathrm{H}$ stretch and $\mathrm{H}-\mathrm{O}-\mathrm{H}$ bend vibrations, increase which also indicates the increase in the water content.

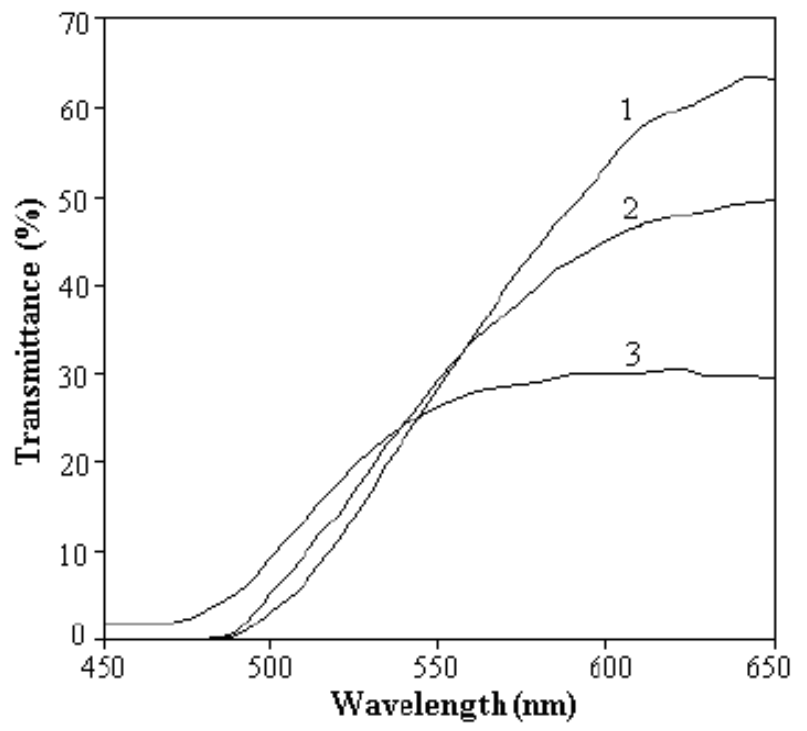

Fig. 9. Variations of transmittance spectra under the action of heat treatment: the as-prepared $\mathrm{V}_{2} \mathrm{O}_{5} \times n \mathrm{H}_{2} \mathrm{O}$ film with $n=1.8$ (1) and that same film annealed at $T=230^{\circ} \mathrm{C}$ (2) and $310^{\circ} \mathrm{C} \mathrm{(3)} \mathrm{(taken} \mathrm{from} \mathrm{[1]} \mathrm{with}$ permission).

We therefore conclude that during the process of EC coloration, apart from the $\mathrm{H}^{+}$redistribution (increase of $x$ ), the value of $\mathrm{n}$ increases too. The results on dehydration presented in Fig. 9 support this conclusion. It is pertinent to note that at low temperatures of heat treatment (below or of the order of $200^{\circ} \mathrm{C}$ ), the shift is rather indistinguishable and it may be even in the opposite direction [36]. However, at higher temperatures the tendency is quite definite, namely, that shown in Fig. 9. From the figure, it is evident that as the water content decreases, the absorption edge shifts toward the short wavelength spectral region and the value of transmittance $T$ falls. In other words, an increase of $\mathrm{n}$ results in an increase of $T$ and in a shift of the edge towards the long-wavelength region. This is exactly what is observed during EC coloration (Fig. 7).

\section{Properties of Vanadium Oxide Subjected to Hydrogen Plasma Treatment}

The temperature dependence of resistance for one of the samples of $\mathrm{V}_{2} \mathrm{O}_{5}$ gel film after treatment in hydrogen plasma is shown in Fig. 10, a (curve 1). This sample was subject to plasma treatment in an RF reactor with remote lowtemperature plasma [29]. One can see that the curve has a distinctive maximum at $T=T_{\mathrm{m}} \approx 100 \mathrm{~K}$.
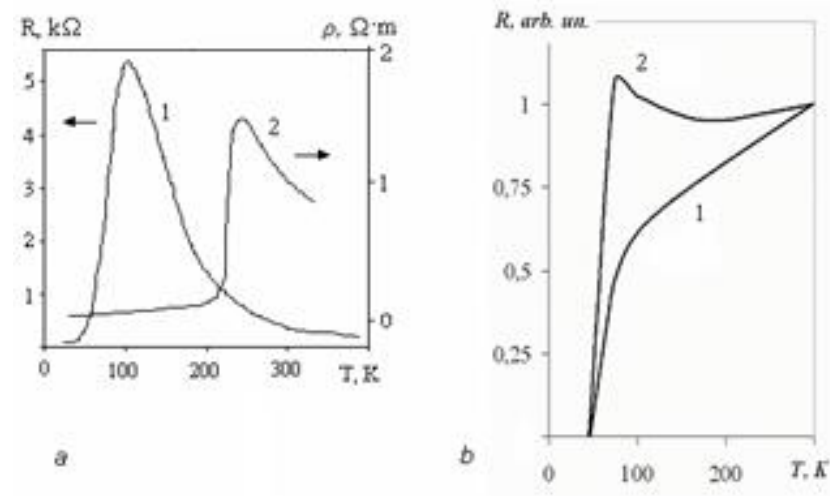

Fig. 10. (a) Temperature dependences of resistance of the vanadium oxide sample subject to plasma treatment (1) and $\mathrm{La}_{0 .} \mathrm{Ca}_{0.3} \mathrm{MnO}_{3}$ (2) (adopted from [37]); (b) Temperature dependences of the normalized resistance $\left(R(T) / R(300 \mathrm{~K})\right.$ of the $\mathrm{SC}$ cuprates $\mathrm{TlCa}_{1-\mathrm{x}} \mathrm{Nd}_{\mathrm{x}} \mathrm{CuO}_{4}$ at $\mathrm{x}=0.25(1)$ and $\mathrm{x}=0.75$ (2) (after Edwards et al. [38]).

Such a behavior of the $R(T)$ dependence might be attributed to an inverse (or re-entrant) MIT [29], which is characteristic of, for instance, CMR-manganites [37] (cf. curves 1 and 2 in Fig. 10, a). However, this might also be an indication of the superconducting (SC) behavior: similar dependence of $R$ on $T$ is characteristic of many under- and over-doped HTSC cuprates (the example of such behavior is shown in Fig. 10, b). Little is known about composition and structure of the vanadium-oxide phase, obtained by the treatment in low-temperature plasma, which is responsible for the observed properties. The difficulties of the samples characterization have been described in [29], and, manifestly, further efforts are necessary to unravel this problem. Presumably, it is some hydrogen bronze of a Magneli-phase lower oxide $\mathrm{V}_{\mathrm{n}} \mathrm{O}_{2 \mathrm{n}-1}$. For example, it could be $\mathrm{H}_{\mathrm{x}} \mathrm{V}_{7} \mathrm{O}_{13}$, which accounts for (in view of aforesaid) the possible SC properties of this specimen (with $T_{c} \sim T_{m}$ - see Fig. 10(a), curve 1). Note that $\mathrm{V}_{7} \mathrm{O}_{13}$ is the only of vanadium oxides remaining metallic down to liquid helium temperatures. Actually, X-ray structural and phase analysis reveals a mixture of lower vanadium oxides. Multi-phase heterogeneous systems exhibit usually well-defined behavior in frequency electrical measurements: $R \sim(f)^{0.7}$ (which also is inherent to hopping conductivity of disordered materials [35]). Actually, similar dependence has been observed for the $\mathrm{V}_{2} \mathrm{O}_{5}$ gel [1] which serves as a precursor for the samples described here.

The dependences of the plasma-treated sample resistance on frequency $f$ at different temperatures are presented in Fig. 11. However, in the process of frequency measurements, we encountered the effect of a shift of the $T_{\mathrm{m}}$ toward higher values as the frequency increases. Such a behavior is often characteristic of relaxor ferroelectrics with frequency-induced shift of $\varepsilon(T)$ curves, as well as of conductivity in spin glasses and materials with specific magnetic phase transitions (like, e.g., quasi-crystal $\mathrm{AlPdMn}_{\mathrm{x}}$ or $\mathrm{CeAl}_{3}$ ) [30].

Note that, as said above, a hydrogen bronze $\mathrm{H}_{\mathrm{x}} \mathrm{V}_{\mathrm{n}} \mathrm{O}_{2 \mathrm{n}-1}$ of a Magneli-phase lower vanadium oxide (predicted in [29] as 
a possible vanadium-based SC phase) might turn out to be a good candidate for HTSC. On the one hand, hydrogen leads to metallization of the initially semiconducting material (see [29] and references therein), and on the other hand, it acts as a ligand promoting SC properties. The point is that initial structures (or precursors) to produce new SC materials could be a material exhibiting a temperature-induced MIT with the metallic state, which is somehow stabilized down to $T=0 \mathrm{~K}$. Presumably, these should be multi-component compounds possessing a high capacity for introducing impurity (desirably, up to $\sim 10 \%$ without the separate phase precipitation) [30]. Other components should be: i) a transition or rare-earth element (e.g., V itself or some additional element) ensuring band narrowness and a high DOS on the Fermi level, and ii) some light ( $\mathrm{H}, \mathrm{Li}, \mathrm{Na}$, etc) element. Note that exactly the very approach is used in the search for SC in transition metal hydrides [30].

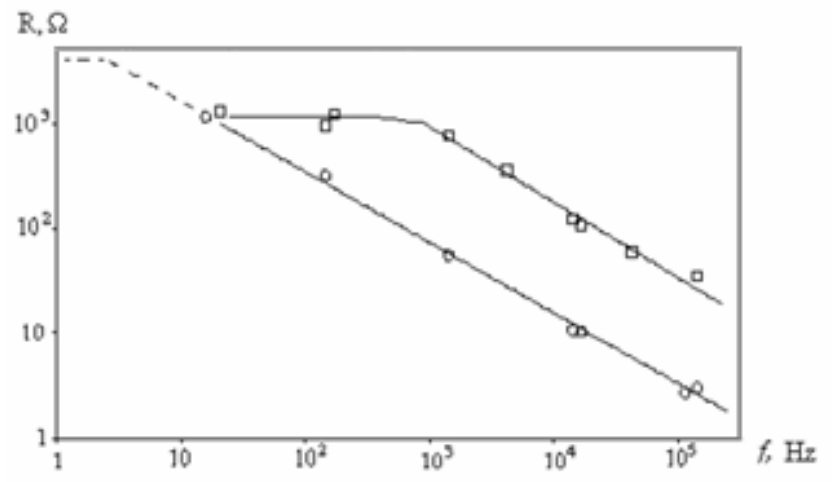

Fig. 11. A.C. resistance of the vanadium oxide sample, subject to plasma treatment, as a function of frequency at $T=20 \mathrm{~K}$ (circles, lower curve) and $293 \mathrm{~K}$ (squares, upper curve).

\section{Electrical Switching and Effect of Doping}

As mentioned above, for moderate current densities ( $I$ $I_{\mathrm{c}}$ ), some electrochemical processes take place leading to the internal EC effect. If the current increases further, EF occurs (Fig. 3, region 4). When the amplitude of the applied voltage reaches the forming voltage, $V_{\mathrm{f}}(\sim 50 \mathrm{~V}$ for the sample of Fig. 3), a sharp and irreversible increase in conductivity is observed and the $I-V$ characteristic of the device becomes S-shaped (Fig. 12) [1], [29], [39]. With increasing current, the $I-V$ characteristic may change until the parameters of the switching structure (threshold voltage $V_{\text {th }}$, OFF-state resistance $R_{\text {off }}$, and others) are finally stabilized. The process outlined above is qualitatively similar to EF of the metal/dielectric/metal (MDM) devices based on amorphous semiconductors and anodic oxide films [1]. It is also similar to the forming processes in planar $\mathrm{V}_{2} \mathrm{O}_{5}$ gel based devices [22], [23], but with lower $V_{\mathrm{f}}$ and $V_{\text {th }}$. For example, for the planar structures studied in [23], $V_{\mathrm{f}}=$ $100-400 \mathrm{~V}$, and $V_{\text {th }}$ was typically $\sim 25 \mathrm{~V}$ for the electrode width $0.5 \mathrm{~mm}$.
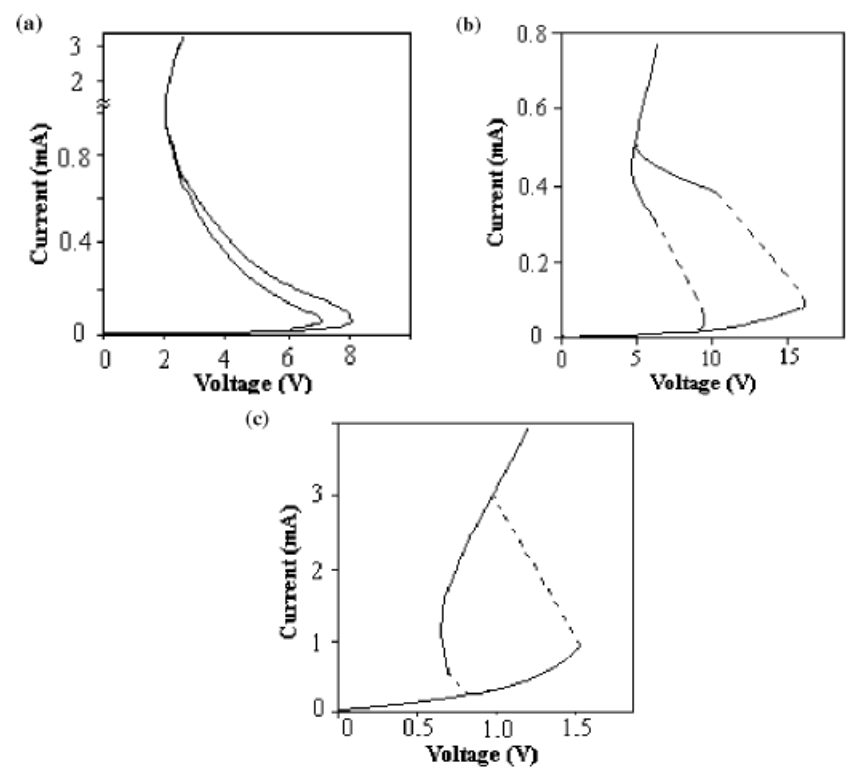

Fig. 12. $I-V$ characteristics of electroformed $\mathrm{M} / \mathrm{xerogel} / \mathrm{M}$ sandwich devices with the $\mathrm{V}_{2} \mathrm{O}_{5}$ gel films of different thickness: (a) $8.4 \mu \mathrm{m}$ (figure 7), (b) $7.0 \mu \mathrm{m}$ and (c) $1.0 \mu \mathrm{m}$. $I-V$ curve of part (a) is recorded under d.c. conditions with $R_{\mathrm{L}} \ll R_{\mathrm{ON}}$, where $R_{\mathrm{L}}$ is the load resistance and $R_{\mathrm{ON}}$ is the ON-state resistance of the device. Curves $(b)$ and $(c)$ are obtained using the standard a.c. oscilloscope method.

Next we studied EF and switching in sandwich $\mathrm{V}_{2} \mathrm{O}_{5} \times n \mathrm{H}_{2} \mathrm{O}$ based devices. The first stage of the forming is thus akin to the conventional electrical breakdown. However, if the postbreakdown current is limited, the breakdown is non-destructive and repetitive switching is then possible, i.e. this results in formation of a switching channel rather than a breakdown channel. The latter would be expected to have metallike conductivity and no negative resistance in the $I-V$ characteristic. It is quite evident that the phase composition of this switching channel must differ from the material of the initial film, because the channel conductivity exceeds that of an unformed structure by several orders of magnitude. As the temperature increases, $V_{\text {th }}$ decreases, tending to zero at some finite temperature $T_{0}$. This temperature practically coincides with the transition temperature of $\mathrm{VO}_{2}: T_{0}=320-340 \mathrm{~K} \approx T_{\mathrm{t}}$. It is concluded, therefore, that the channel consists (completely or partly) of vanadium dioxide and switching is associated with the metal insulator transition in $\mathrm{VO}_{2}$, which is in accordance with the literature data for planar $\mathrm{V}_{2} \mathrm{O}_{5}$ gel structures [22], [23].

The switching parameters vary by up to an order of magnitude for different structures. Such a wide range of variation of the $V_{\text {th }}$ and $R_{\text {off }}$ values leads to the conclusion that the resistance and threshold parameters are mainly determined by the forming process. Conditions of EF cannot be unified in principle, because its first stage is associated with conventional electrical breakdown. The phenomenon of electrical breakdown is statistical in nature, and the statistical character of the EF process shows itself as a spread in the observed forming voltages. As a result, the diameter and precise phase composition of the ensuing 
channel (and, consequently, its effective specific conductivity) vary with position in the sample and for different samples. This accounts for the scatter in the $R_{\text {off }}$ and threshold parameters of the electroformed devices.

The threshold voltage at room temperature is typically 10-20V, but it can be less than $10 \mathrm{~V}$ and even down to $\sim 1$ $\mathrm{V}$ for thinner films (Fig. 12, c). Unlike pure stoichiometric $\mathrm{VO}_{2}$ single crystals, in which the conductivity jump at the transition reaches up to five orders of magnitude [2], in the $\mathrm{V}_{2} \mathrm{O}_{5} \times n \mathrm{H}_{2} \mathrm{O}$ based sandwich structures, the jump $R_{\text {off }} / R_{\text {on }}$ is only one to two orders. This suggests that, in the switching channel, the vanadium dioxide phase forms as separate filaments or inclusions, and the channel does not consist completely of $\mathrm{VO}_{2}$. In addition, this might be related to the oxygen nonstoichiometry, which lowers $T_{\mathrm{t}}$ and suppresses the transition [2], [39]. Note that the forming process may be brought about by laser irradiation, not by applying electric field [40]. In the case of laser treatment (or 'laser forming', unlike the above described electrical forming) the parameters of the structures are characterized by the absence of the scatter, i.e. the $I-V$ characteristics of all structures are almost identical.

Next, we have doped the vanadium oxide gel with tungsten as described above in Section 2 (see also [10] where the process of doping is described in more detail). The films deposited from such a gel represent the following composition: $\mathrm{V}_{2-\mathrm{y}} \mathrm{W}_{\mathrm{y}} \mathrm{O}_{5 \pm \delta} \times n \mathrm{H}_{2} \mathrm{O}$, where $\mathrm{y}$ is varied from zero (pure $\mathrm{V}_{2} \mathrm{O}_{5}$ gel) to 0.12 and $\mathrm{n}=1.6-1.8$. These films, after vacuum annealing, transform into vanadium dioxide doped with tungsten. Influence of doping on the electrical properties of $\mathrm{VO}_{2}$ is demonstrated by Fig. 13. An increase in the $\mathrm{W}$ content leads to a decrease in the resistivity of the sample and in a shift of the transition temperature $T_{t}$ towards the low-temperature region. In addition, some modification of the hysteresis loop parameters is observed, as is discussed in the work [10]. At the impurity content of more than 6 at. \%, the MIT no longer occurs, though the $R(T)$ dependence remains still semiconducting (Fig. 13, curve 3 ). Note that for the complete metallization of $\mathrm{VO}_{2}$, the concentration of $\mathrm{W}$ dopant should be $~ 14$ at. \% [41].

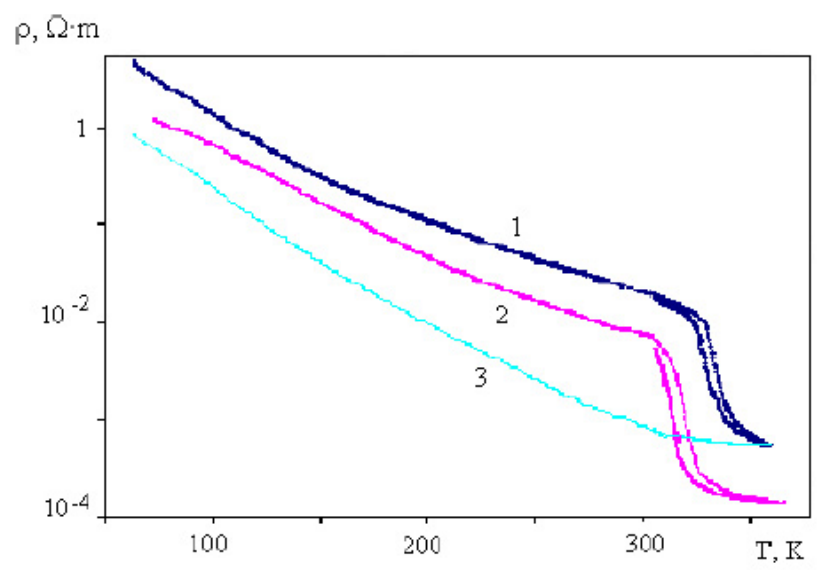

Fig. 13. Resistivity versus temperature for vanadium dioxide (1) and for $\mathrm{VO}_{2}$ doped with 3 at.\% (2) and 12 at.\% (3) of tungsten.
Lastly, we have studied the switching effect in the MDM structures on the basis of $\mathrm{W}$-doped $\mathrm{V}_{2} \mathrm{O}_{5}$ gel films. These structures, as discussed above, require preliminary electroforming resulting in formation of a conducting channel within the initial dielectric film. The channel consists of vanadium dioxide and switching is associated with the insulator-to-metal transition in $\mathrm{VO}_{2}$. As shown in [1], for the pure (undoped) $\mathrm{V}_{2} \mathrm{O}_{5}$ gel, the switching parameters vary over a wide range, because the phenomenon of electrical forming is statistical in nature (likewise electrical breakdown), and its statistical character shows itself as a spread in the observed threshold voltages of the ensuing structures.

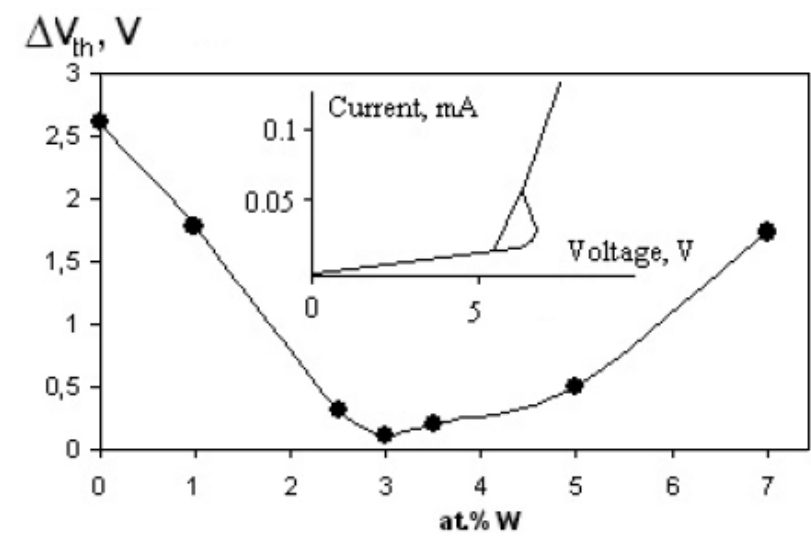

Fig. 14. Threshold range ( $\mathrm{V}_{\text {th }}$ scattering) as a function of $\mathrm{W}$ admixture percentage. A typical $I-V$ curve of $\mathrm{Au}-\mathrm{V}_{2-\mathrm{y}} \mathrm{W}_{\mathrm{y}} \mathrm{O}_{5} \times \mathrm{nH}_{2} \mathrm{O}-\mathrm{Au}$ sandwich structure with $\mathrm{y}=0.03$ is shown in the inset. Thickness for all the samples is $d \sim 1 \mu \mathrm{m}$ and the mean value of $V_{\text {th }}$ is actually independent of $\mathrm{W}$ concentration; $\left\langle V_{\mathrm{th}}\right\rangle=(7.1 \pm 1.5) \mathrm{V}$ with the reliability of 0.95 .

It has been found that the statistical spread in values of the threshold parameters can be minimized by means of doping (Fig. 14). Unsophisticated reasoning could account for this result: for pure $\mathrm{V}_{2} \mathrm{O}_{5}$ gel, electroforming leads to formation of $\mathrm{VO}_{2}$ with $T_{t}=340 \mathrm{~K}$, and each switching event requires heating up and cooling down from room temperature to $T_{\mathrm{t}}$; this thermal cycling can modify the peripheral regions of the channel, which leads to the change of the switching threshold voltage. On the other hand, for the samples with a high concentration of W, the MIT is suppressed (see Fig. 13, curve 3) and switching is degenerated. Between these two outermost points, an optimum should exist. As one can see from figure 14, this optimal value corresponds to 3 at.\% of $\mathrm{W}$, i.e. for $\mathrm{V}_{0.97} \mathrm{~W}_{0.03} \mathrm{O}_{2}$ the switching parameters are the most stable. The transition temperature of $\mathrm{V}_{0.97} \mathrm{~W}_{0.03} \mathrm{O}_{2}$ (Fig. 13, curve 2) is lower than that for pure vanadium dioxide, and hence the magnitude of the aforesaid thermal cycling is decreased, which results in an increase in stability of the switching parameters.

Also, thin films of tungsten-doped and pure vanadium dioxide with a metal-insulator transition prepared by the 
sol-gel method have been studied in the work [28]. The films are characterized by X-ray diffraction, and electrical conductivity is measured in a temperature range from 50 to $380 \mathrm{~K}$. It is shown that the conductivity of the films varies with temperature as $\sigma \sim \exp (a T-b / T)$. The experimental results are discussed from the viewpoint of the small polaron hopping conduction theory taking into account the influence of thermal lattice vibrations onto the resonance integral, and the values of the activation energy and polaron radius are found. It is shown that doping with tungsten affects severely onto the electrical properties of vanadium dioxide [28].

\section{E. Vanadium Oxide Nano-Fibers Obtained from $\mathrm{Gel}$}

Vanadium oxide fibers were formed from a solution of $\mathrm{VO}(\mathrm{acac})_{2}$ in methanol, with addition of PVP polymer, by an electrospinning method, as described in Section 2 above. First we describe here the effect of the PVP concentration and the electrospinning parameters onto the characteristics of the obtained vanadium oxide micro- and nano-fibers [42].

When the PVP concentration is relatively low (region 1-2 in Fig. 15), the vanadium oxide fibers are either not formed at all, or they are formed with large defects in the form of droplets. The variation of the potential difference and distance between the needle tip and substrate does not reduce the fiber defectiveness. A further increase in polymer concentration (region 3-5 in Fig. 15) promotes the reduction of defectiveness and improves the quality of the synthesized microfibers. Also, as the PVP concentration increases, the average fiber length increases too. The fiber images obtained under an optical microscope are shown in figures 16 and 17.

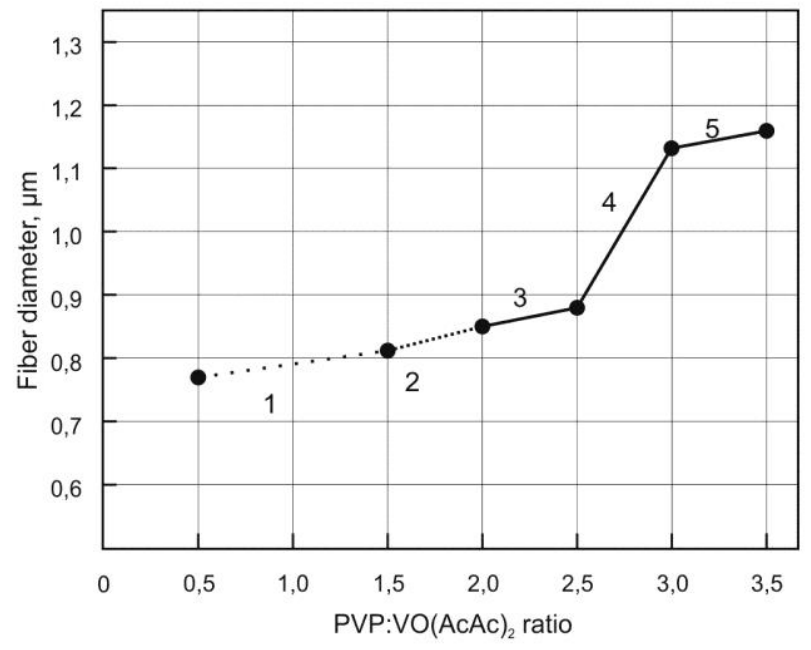

Fig. 15. Effect of $\mathrm{PVP} / \mathrm{VO}(\mathrm{acac})_{2}$ solution ratio upon the maximum diameter of the synthesized fibers of vanadium pentoxide.
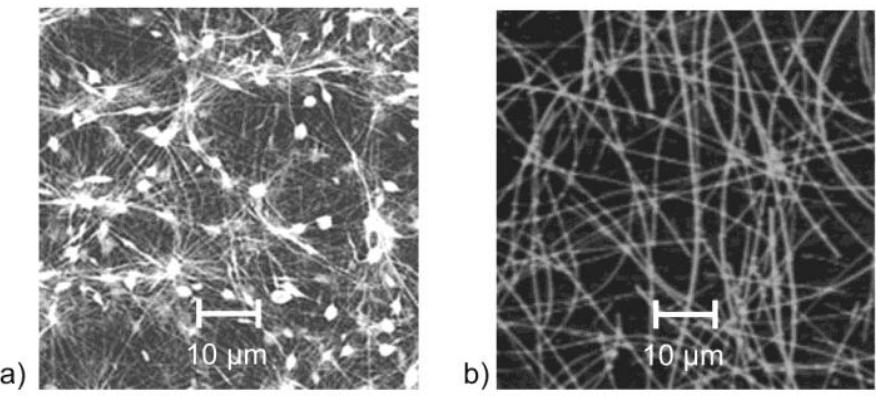

Fig. 16. Microscope images of vanadium oxide fibers obtained at the PVP:VO(acac)2 ratios: a) 1.5:1 (droplet-like defects are seen) and b) 3:1 [42].

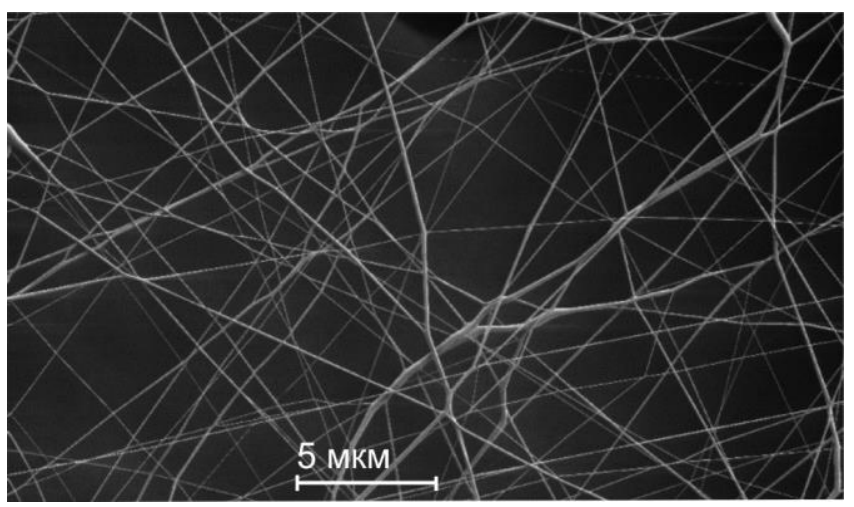

Fig. 17. Microscope images of vanadium oxide fibers after annealing [42] (mark size corresponds to $5 \mu \mathrm{m}$ ).

After the process of electrospinning and fiber synthesis, the fibers are annealed to remove polymer and form crystalline vanadium oxide. Annealing is performed in a muffle furnace in an atmosphere of wet nitrogen. After the heat treatment the minimum fiber diameter ranges from 80 to $600 \mathrm{~nm}$ and depends on the annealing temperature and duration. XRD of the fibers annealed for 60 minutes at $500^{\circ} \mathrm{C}$ (Fig. 18) reveals the complete removal of PVP and formation of the $\mathrm{V}_{2} \mathrm{O}_{5}$ phase.

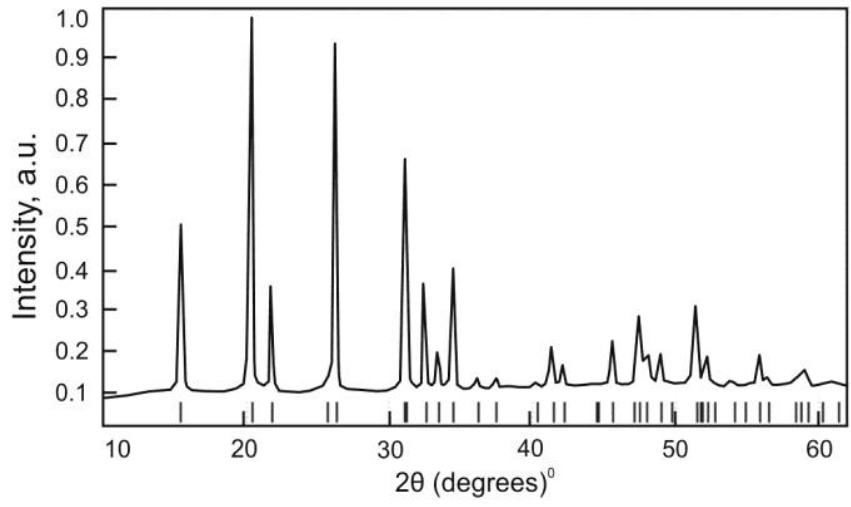

Fig. 18. XRD pattern of fibers obtained at PVP:VO $(a c a c)_{2}=2: 1$ and annealed at $T=500^{\circ} \mathrm{C}$ for 1 hour and Bragg bar chart for $\mathrm{V}_{2} \mathrm{O}_{5}$ with lattice parameters $a=11.48 \AA, b=4.36 \AA$, and $c=3.55 \AA$. 
Investigation of the electrical properties of the vanadium oxide microfibers shows the occurrence of the switching effect (Fig. 19, I-V curves 3 and 4) due to the MIT in vanadium dioxide. The fact that switching is associated with the MIT in $\mathrm{VO}_{2}$ is confirmed by the following test: as the temperature increases, the threshold voltage decreases tending to zero at $T \sim T_{\mathrm{t}}(\sim 340 \mathrm{~K})$. This experiment confirms that the proper annealing regimes [42] provide a sufficient amount of the vanadium dioxide phase (Fig. 19, curves 3 and 4).

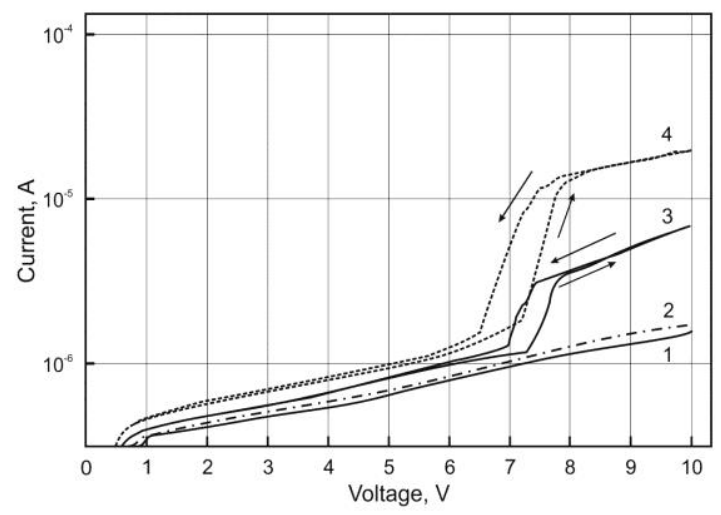

Fig. 19. $I-V$ characteristics of the fibers $\left(\mathrm{PVP}: \mathrm{VO}(\mathrm{acac})_{2}=3: 1\right)$ on glassceramic substrate with $\mathrm{Au}$ electrodes. The fibers were previously annealed at different regimes: $1-T=400^{\circ} \mathrm{C}, t=40 \mathrm{~min}$., $2-450^{\circ} \mathrm{C}, 40 \mathrm{~min} ., 3-$ $450^{\circ} \mathrm{C}, 60 \mathrm{~min}$., and $4-500^{\circ} \mathrm{C}, 60 \mathrm{~min}$. plus heating up to $600^{\circ} \mathrm{C}$ for 10 $\min$.

Finally, vanadium oxide gel films have been obtained by the acetylacetonate gel method on Kapton (Fig. 20) [42] which is of particular importance for possible applications in flexible electronics.

Summarizing, vanadium oxide films and fibers have been successfully fabricated by the acetylacetonate sol-gel method followed by annealing in wet nitrogen. The effect of annealing parameters on the structures and properties of vanadium oxide films have been studied, and it is shown that the optimal temperature regime for formation of the relatively pure and well crystallized $\mathrm{VO}_{2}$ phase is as follows: warming-up at $550^{\circ} \mathrm{C}$ for $35 \mathrm{~min}$. with subsequent heating up to $600^{\circ} \mathrm{C}$ during $5 \mathrm{~min}[42]$.

\section{CONCLUSION}

In this brief review we have described the optical and electrical properties of hydrated vanadium oxide films deposited by sol-gel process. It is shown that the films exhibit such phenomena as "internal" electrochromism and electrical switching [1], [26].

Under cathodic polarization, the films turn from brownish-yellow to dark-red due to an increase of the hydrogen concentration. In addition, according to the IR data, some increase in water content also contributes to the $\mathrm{EC}$ coloration. These processes result in modification of the optical and electrical properties of the films, namely - in the shift of the absorption edge toward the red spectrum region and the increase in the ionic conductivity. This internal EC effect is quite reversible, i.e. under anodic polarization the process of bleaching occurs.

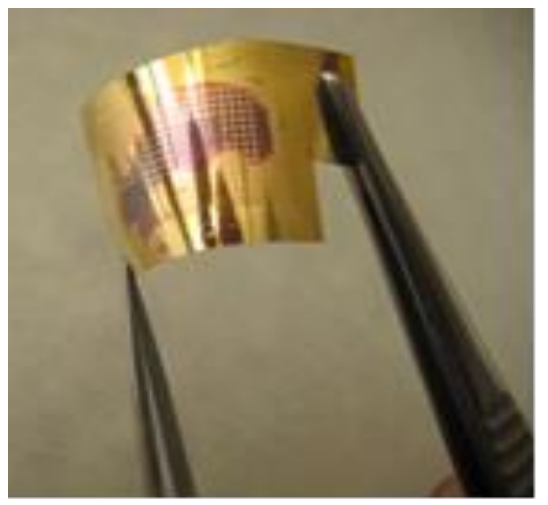

Fig.20. Vanadium oxide switching structures on Kapton.

At higher currents, electroforming resulted from the transport of oxygen ions occurs. The process of EF leads to the formation of a channel consisting of vanadium dioxide due to reduction of $\mathrm{V}_{2} \mathrm{O}_{5}$ to $\mathrm{VO}_{2}$. Reversible switching with the S-type negative resistance, associated with an electrothermally driven metalinsulator transition in the channel, is then observed. It is important to stress that the switching experiments have been performed in this study on the sandwich, not planar, $\mathrm{M} / \mathrm{V}_{2} \mathrm{O}_{5} \times$ $n \mathrm{H}_{2} \mathrm{O} / \mathrm{M}$ devices. Some applied aspects of the obtained results have been discussed. The most obvious of them are electrolyteless EC devices, as well as microsensors based on the temperature and pressure dependences of the switching parameters [1], [15], [26].

Also, the effect of doping with $\mathrm{H}$ and $\mathrm{W}$ ions on the properties of vanadium oxide gel films has been studied [7], [10], [28]-[30], [39]. It is shown that doping with tungsten and hydrogen affects severely the electrical properties of vanadium oxides. The treatment of $\mathrm{V}_{2} \mathrm{O}_{5}$ in low-temperature hydrogen plasma leads to either hydration of vanadium pentoxide or its reduction to lower vanadium oxides. Doping of $\mathrm{VO}_{2}$ with $\mathrm{W}$ leads to a decrease of the transition temperature, which is in accordance with the literature data and supports the Mott mechanism of MIT in vanadium dioxide [10]. Possible superconductivity in lower hydrated vanadium oxides is discussed [29], [30]. Note that HTSCmaterials based on vanadium oxides (with the suppressed MIT) are actively discussed in the scientific literature (see, e.g., [43]).

Lastly, the acetylacetonate gel technique has been developed [7], [42] and vanadium oxide films and fibers obtained from this gel have been studied. It is shown that the proposed procedures for the preparation of vanadium oxide thin films and quasi-1D fiber structures, based on the vanadyl acetylacetonate sol-gel route, are promising in terms of developing functional devices of oxide nanoelectronics [2].

Acknowledgment

The authors thank G. B. Stefanovich, V. P. Zlomanov, and A. L. Pergament for helpful discussions. 


\section{REFERENCES}

[1] A. L. Pergament, E. L. Kazakova and G. B. Stefanovich, "Optical and electrical properties of vanadium pentoxide xerogel films: modification in electric field and the role of ion transport", Journal of Physics D: Applied Physics, vol. 35, pp. 2187-2197, 2002.

[2] A. L. Pergament, G. B. Stefanovich, A. A. Velichko, "Oxide Electronics and Vanadium Dioxide Perspective: A Review", Journal on Selected Topics in Nano Electronics and Computing vol. 1, pp. 24-43, 2013.

[3] J. Livage. "Vanadium pentoxide gels", Chemistry of Materials, vol. 3, no. 4, pp. 578-593, 1991.

[4] Y. Dachuan, X. Niankan, Z. Jingyu and Z. Xiulin, "Vanadium dioxide films with good electrical switching property", Journal of Physics D: Applied Physics, vol. 29, no. 4, pp. 1051-1057, 1996.

[5] N. Gharbi, C.R. Kha, D. Ballutaud, M. Michaud and J. Livage, "A new vanadium pentoxide amorphous phase", Journal of Noncrystalline Solids, vol. 46, no. 3, pp. 247-257, 1981.

[6] M. Pan, H. Zhong, S. Wang, J. Liu, Z. Li, X. Chen, W. Lu, "Properties of VO2 thin film prepared with precursor VO(acac)2", Journal of Crystal Growth, vol. 265, no. 1, pp. 121-126, 2004.

[7] O.J. Berezina, V.P. Zlomanov, D.A. Kirienko, A.L. Pergament, S.S Tatevosjan, D.S. Jakovleva, "Influence of the preparation conditions and doping on the properties of the vanadium oxides films", Modern Problems of Sci. and Education, no. 4, 2013. Available: http://www.science-education.ru/en/110-r9646.

[8] P. Aldebert, N. Baffier, N. Gharbi and J. Livage, "Layered structure of vanadium pentoxide gels", Materials Research Bulletin, vol. 16, no. 6, pp. 669-676, 1981.

[9] S. Sakka (Ed.) Handbook of Sol-Gel Science and Technology. Processing, Characterization and Applications. Berlin: Kluwer Academic Publishers (Springer) 2005.

[10] O. Ya. Berezina, A. A. Velichko, L. A. Lugovskaya, A. L. Pergament, G. B. Stefanovich, "Metal-semiconductor transition in nonstoichiometric vanadium dioxide films", Inorganic Materials, vol. 43, no. 5, pp. 505-511, 2007.

[11] J. Livage, O. Pelletier and P. Davidson, "Vanadium Pentoxide Sol and Gel Mesophases", Journal of Sol-gel Science and Technology, vol. 19, no. 1, pp. 275-278, 2000.

[12] A.L. Pergament and G.B. Stefanovich, "Phase composition of anodic oxide films on transition metals: a thermodynamic approach", Thin Solid Films, vol. 322, no. 1, pp. 33-36, 1998.

[13] C. Sanchez, F. Babonneau, R. Morineau and J. Livage, "Semiconducting properties of V2O5 gels", Philosophical Magazine Part B, vol. 47, no. 3, pp. 279-290, 1983.

[14] Dane T. Gillaspie, Robert C. Tenent and Anne C. Dillon, "Metaloxide films for electrochromic applications: present technology and future directions", Journal of Materials Chemistry, vol. 20, pp. 9585-9592, 2010.

[15] E. L. Kazakova, "Electron and ion processes in hydrated vanadium pentoxide", Ph.D. dissertation, Dept. Phys. Eng., Petrozavodsk State Univ., Petrozavodsk, RF, 2002.

[16] S. F. Cogan, N. M. Nguyen, S. L. Perrotti, and R. D. Rauh, "Optical properties of electrochromic vanadium pentoxide", J. Appl. Phys., vol. 66, pp. 1333 - 1337, 1989.

[17] A. Surca, and B. Orel, "IR spectroscopy of crystalline V2O5 films in different stages of lithiation”, Electrochimica Acta, vol. 44, no. 18, pp. 3051-3057, 1999.

[18] A. Talledo, and C.G. Granqvist, "Infrared absorption in lithiumintercalated vanadium pentoxide films", J. Phys. D: Appl. Phys., vol. 27, no. 11, pp. 2445-2447, 1994

[19] G. J. Fang, Z. L. Liu, Y. Q. Wang, H. H. Liu, and K. L. Yao, "Orientated growth of $\mathrm{V}_{2} \mathrm{O}_{5}$ electrochromic thin films on transparent conductive glass by pulsed excimer laser ablation technique", $J$. Phys. D: Appl. Phys., vol. 33, no. 23, pp. 3018-3021, 2000.

[20] N. Özer, "Electrochemical properties of sol-gel deposited vanadium pentoxide films", Thin Solid Films, vol. 305, no. 1, pp. 80-87, 1997.

[21] E. E. Chain, "Optical properties of vanadium dioxide and vanadium pentoxide thin films" Appl. Opt., vol. 30, no. 19, pp. 2782-2787, 1991

[22] J. G. Zhang, P. C. Eklund, "The switching mechanism in V2O5 gel films", J. Appl. Phys. vol., 64, pp. 729-733, 1988.
[23] J. Bullot, O. Gallias, M. Gauthier, and J. Livage, "Threshold switching in V2O5 layers deposited from gels", Phys. Status Solidi (a), vol. 71, no. 1, pp. K1-K4, 1982.

[24] T. Coradin, M. Boissiere, and J. Livage, "Sol-gel Chemistry in Medicinal Science", Curr. Med. Chem., vol. 13, no. 1, pp. 99-108, 2006.

[25] A. Pergament and A. Velicko, "Metal-insulator transition in thin films of vanadium dioxide: The problem of dimensional effects", Thin Solid Films, vol. 518, pp. 1760-1762, 2010.

[26] G. B. Stefanovich, A. L. Pergament, and E. L. Kazakova, "Electrical switching in metal-insulator-metal structures based on hydrated vanadium pentoxide", Tech. Phys. Lett. vol. 26, no. 6, pp. 478-480, 2000.

[27] F. A. Chudnovskii, L. L. Odynets, A. L. Pergament, and G. B. Stefanovich, "Electroforming and Switching in Oxides of Transition Metals: The Role of Metal-Insulator Transition in the Switching Mechanism”, J. Solid State Chem. vol. 122, no. 1, pp. 95-99, 1996.

[28] A. Pergament, G. Stefanovich, O. Berezina, D. Kirienko, "Electrical conductivity of tungsten doped vanadium dioxide obtained by the sol-gel technique", Thin Solid Films, vol. 531, pp. 572-576, 2013.

[29] A. L. Pergament, A. A. Velichko, O. Ya. Berezina, E. L. Kazakova, N. A. Kuldin, and D. V. Artyukhin, "Influence of doping on the properties of vanadium oxide gel films", J. Phys.: Condens. Matter vol. 20 , no.42, pp. $422204-422207,2008$.

[30] A. L. Pergament and A. Kuldin (2008), "Electrical properties of vanadium oxide subject to hydrogen plasma treatment", Available: http://arxiv.org/abs/0812.2973.

[31] J. Doshi and D. H. Reneker, "Electrospinning Process and Applications of Electrospun Fibers", Journal of Electrostatics, vol. 35, pp. 151-160, 1995.

[32] J. C. Badot, A. Fourrier-Lamer, N. Baffier, "Dielectric study of $\mathrm{V}_{2} \mathrm{O}_{5}-1.6 \mathrm{H}_{2} \mathrm{O}$ xerogel in the broad frequency range $\left(10^{5}-10^{10} \mathrm{~Hz}\right)$, J. Phys. (Paris), vol. 46, no. 12, p. 2107, 1985.

[33] N. Özer and C. Lampert, "Structural and optical properties of sol-gel deposited proton conducting Ta2O5 films", J. Sol-Gel Sci. Technol., vol. 8, no. 1, pp. 703-709, 1997.

[34] J. S. Rez, Yu. M. Poplavko, Dielectrics: Basic Properties and Applications in Electronics, Moscow: Radio, 1989.

[35] N. F. Mott, E. A. Davis. Electronic Processes in Non-Crystalline Materials, 2nd ed., Oxford: Clarendon, 1979.

[36] Z. S. El Mandouh and M.S. Selim, "Physical properties of vanadium pentoxide sol gel films", Thin Solid Films, vol. 371, no. 1, pp. 259263, 2000.

[37] A. M. Haghiri-Gosnet and J. P. Renard, "CMR manganites: physics, thin films and devices", J. Phys. D: Appl. Phys., vol. 36, no. 8, pp. R127-R150, 2003.

[38] P. P. Edwards, T. V. Ramakrishnan, C. N. Rao, "The MetalNonmetal Transition: A Global Perspective", J. Phys. Chem., vol. 99, no. 15, pp. 5228-5239, 1995

[39] A. Pergament, A.Velichko, V. Putrolaynen, G. Stefanovich, N. Kuldin, A. Cheremisin, I. Feklistov, N. Khomlyuk, "Electrical and optical properties of hydrated amorphous vanadium oxide", J. Phys. D: Appl. Phys., vol. 41, no. 22, pp. 225306-225308, 2008.

[40] G. B. Stefanovich, A. L. Pergament, V. P. Malinenko, and D. O. Kikalov, "Laser modification of the properties of transition metal oxides", in Proc. 7th Nordic Conf. in Laser Processing of Materials, ed. V. Kujanpaa and J. Ion (Lappeenranta, Finland: Acta Universitatis Lappeenrantaensis)1999, p 552.

[41] D. B. McWhan, J. P. Remeika, J. P. Maita, "Heat capacity of vanadium oxides at low temperature", Phys. Rev. vol. 7, no. 1, pp. 326-332, 1973.

[42] D. A. Kirienko "Switching and electrochromic effect in nano- and micro-structures based on transition metal oxides", Ph.D. dissertation, Dept. Phys. Eng., Petrozavodsk State Univ., Petrozavodsk, RF, 2013.

[43] M. Marezio, A Gauzzi, F Licci, E Gilioli, "Can the structure of the Ti or V Magnéli binary oxides host superconductivity?”, Physica C, vol. 338, no. 1-2, pp. 1-8, 2000. 